\title{
Hydride Approach in Blended Elemental Powder Metallurgy of Beta Titanium Alloys
}

\author{
O.M.Ivasishin ${ }^{1,2}$, D.G.Savvakin ${ }^{1 *}$, D.V.Oryshych ${ }^{1}$, O.O.Stasiuk $^{1}$, Li Yuanyuan ${ }^{2}$ \\ ${ }^{1}$ G.V. Kurdyumov Institute for Metal Physics, 36, Vernadsky Str., Kyiv, 03142, Ukraine \\ 2 Jilin University, 2699 Qianjin Str., Changchun, 130012, China \\ *savva@imp.kiev.ua
}

\begin{abstract}
The physical bases of hydrogenated titanium powders application in blended elemental powder metallurgy (BEPM) of titanium alloys were earlier developed. Hydrogen as temporary alloying addition for titanium strongly affects diffusion processes upon transformation of powder blends into alloys ensuring production of $\alpha+\beta$ and metastable $\beta$ titanium alloys which mechanical properties meet standard requirements. At the same time, synthesis of metastable $\beta$ alloys is complicated by a big amount of alloying elements which diffusion redistribution upon sintering has a strong impact on microstructure evolution.

In present study BEPM hydride approach was expanded for production of biocompatible low modulus Ti-Zr-Nb and Ti-Zr-Nb-Ta alloys having BCC structure which are attractive materials for medical application. The alloys of prescribed compositions were produced using various starting powders, including $\mathrm{TiH}_{2}, \mathrm{ZrH}_{2}$, hydrogenated niobium, tantalum and Ti-Nb master alloys. Peculiarities of volume changes of multicomponent powder blends on dehydrogenation were investigated. The specific volume changes of powder components during dehydrogenation affect densification kinetic of powder blends and microstructure of as-sintered alloys.
\end{abstract}

\section{Introduction}


Blended elemental powder metallurgy (BEPM) has a great potential for manufacturing of titanium components [1] owing to significant cost reduction as compared to conventional cast/wrought manufacturing approach. The use of hydrogenated titanium (titanium hydride $\mathrm{TiH}_{2}$ ) powder instead of titanium metal powder blended with alloying particles provides an unique opportunity to achieve mechanical properties sufficient for many practical applications of BEPM produced titanium parts [2-3]. In this approach (further referred as $\mathrm{TiH}_{2}$ BEPM) hydrogen serves as a temporary alloying element for titanium affecting its microstructure and, therefore, mechanical properties. $\mathrm{TiH}_{2}{ }^{\circledR} \mathrm{Ti}+2 \mathrm{H}$ phase transformation takes place upon vacuum heating of hydrogenated titanium. The phase transformation increases density of crystal lattice defects, activates solid state diffusion, thus resulting in faster homogenization and densification of powder blends. Atomic hydrogen released from each $\mathrm{TiH}_{2}$ particle reduces surface $\mathrm{TiO}_{2}$ layer on them. Cleaning of the particle surface makes them open for interparticle diffusion. Open porosity provides the pathway for $\mathrm{H}_{2} \mathrm{O}$ vapor to go out. As a result, oxygen content in the compact is being decreased [4]. Hydrogen also takes away some other impurities from the particle surface, such as chlorine and carbon. The former is especially important since the chlorine rich powder in solid state PM processing always result in the poor ductility and corresponding decrease in the properties [5]. If properly done, the $\mathrm{TiH}_{2} \mathrm{BEPM}$ that includes dehydrogenation, sintering and chemical homogenization of powder blends (Fig 1) results in production of nearly dense (up to $99 \%$ ) chemically and microstructurally homogeneous $\alpha+\beta$ and near- $\beta$ titanium products with admissible impurity content and mechanical properties which met requirements and specifications for corresponding cast/wrought materials [2-3, 6-7]. However, homogenization and densification of powder blends and hence, microstructure of alloy products are strongly affected by their composition and type of alloying powders (AP - elemental metals or master alloys) used in the blends to attain prescribed chemical composition. Formation of low-porous and fine-grained as-sintered microstructures has proved to be especially challenging for near- $\beta$ compositions with high content of alloying elements, such as high-strength Ti-10V-2Fe-3Al, Ti-5Al-5V$5 \mathrm{Mo}-3 \mathrm{Cr}$ [2-3] and Ti-1Al-8V-5Fe alloys. It has been found that although $\mathrm{TiH}_{2} \mathrm{BEPM}$ is advantageous compared to conventional Ti PM, its specific features have to be taken into account at manufacturing titanium compositions with higher content of alloying elements.

\section{$\underline{\mathrm{TiH}_{2}} \underline{\text { BEPM processing of metastable } \beta \text { alloys }}$}

The base $\mathrm{TiH}_{2}$ particles and AP particles form two subsystems with numerous interfaces between particles of different subsystems. Dehydrogenation results in a significant shrinkage of $\mathrm{TiH}_{2}$ particles, only slightly compensated by thermal expansion, while AP are subjected to thermal expansion only. Such mismatch in volume changes makes $\mathrm{TiH}_{2} / \mathrm{AP}$ interfaces weak elements of the 
powder compacts further leading to their damaged integrity. Formation of gaps and voids at such interfaces adds to the porosity and retards densification. Another issue is a delayed homogenization since corresponding contact areas become smaller and which is generally slow in such alloys because of low diffusion mobility of many $\beta$ stabilizers ( $\mathrm{Mo}, \mathrm{Nb}, \mathrm{Ta}$ ) in titanium. Higher temperatures and/or longer times of sintering cannot be a solution for an optimized processing since this leads to coarsening of grain structure.

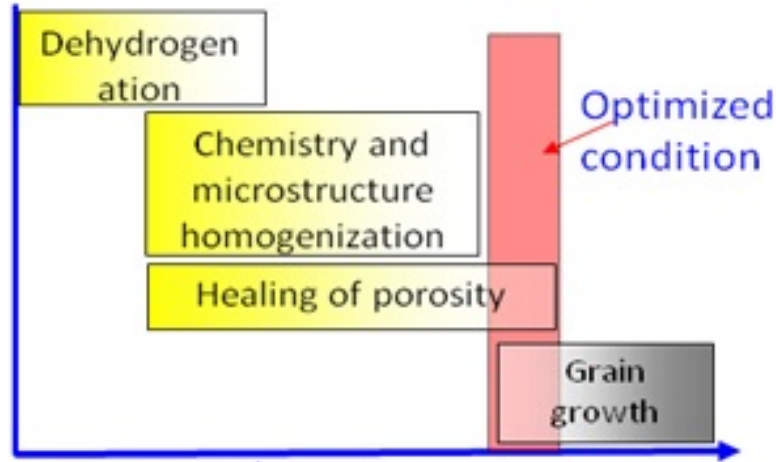

Integrated sintering parameter (includes temperature and time)

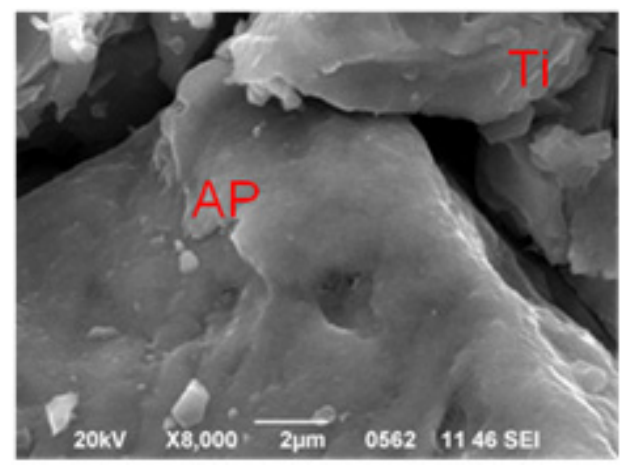

Fig. 1. Schematic illustration of phase and microstructure evolution upon $\mathrm{TiH}_{2}$ BEPM.
Fig. 2 Gap formed between AP and dehydrogenated titanium matrix (Ti1023 composition). 
The above issues of $\mathrm{TiH}_{2}$ BEPM processing of metastable $\beta$ alloys were partly overcome by proper selection of alloying powders, their sizing and modification of sintering parameters [2-3]. However, for some compositions such methods were not sufficient to achieve desirable microstructures and properties.

This study was aimed at analysis of potential pathways for further improvement of $\mathrm{TiH}_{2}$ BEPM manufacturing of heavily alloyed titanium alloys. The main strategy was to minimize a difference in volume mismatch on $\mathrm{TiH}_{2}$ /AP interfaces in order to minimize the reasons of gap/void formation. In principle, there are two possibilities for that. Since dehydrogenation of $\mathrm{TiH}_{2}$ particles is a dominant process, the first possibility is based on the assumption that such shrinkage should be compensated by expansion of the AP in the same temperature range. It would be possible if AP particles absorb the part of hydrogen released from the $\mathrm{TiH}_{2}$ particles and expand due to their hydrogenation.

More promising is a second possibility based on a selection of AP which particles behave similar to $\mathrm{TiH}_{2}$ particles upon compaction and heating. It is known [2] that compaction mechanism of the $\mathrm{TiH}_{2}$ particles includes their crushing and forming specific locks between crushed pieces, strong enough to keep them together upon handling of the green parts and following heating. This ensures compact integrity despite of shrinkage of each individual particle. So, if the AP particles would exhibit the mechanical properties similar to that of the $\mathrm{TiH}_{2}$ particles, namely brittleness and low strength, they would be involved in the formation of compact similar to the compact consisted of the $\mathrm{TiH}_{2}$ particles only. To satisfy the above requirements to the AP it is proposed to use their hydrogenated modifications.

Both approaches were tested at $\mathrm{TiH}_{2}$ BEPM processing of high-strength Ti-1Al-8V-5Fe alloy. Ingot of $18 \mathrm{Ti}-6 \mathrm{Al}-47 \mathrm{~V}-29 \mathrm{Fe}$ (mass.\%) master alloy was melted and crushed to powder. Part of the AP was compacted with $\mathrm{TiH}_{2}$ powder. It was important that material of such composition could undergo hydrogenation/dehydrogenation cycle [8] upon heating. So we could believe that AP hydrogenation would be in favor of compact integrity. Another part was preliminary hydrogenated and then compacted together with $\mathrm{TiH}_{2}$ powder as a blend of two hydride powders.

Shrinkage curves for both such compacts are shown on Fig. 3. One can see that they are quite similar. Moreover, overall linear shrinkage was in excess of $10 \%$, the same as that typically observed upon sintering of the pure $\mathrm{TiH}_{2}$ powder. This was expected for the blend that included 
preliminary hydrogenated AP (curve 1) but similar shrinkage behavior of the blend with non hydrogenated AP was even above expectations (curve 2) clearly indicating that AP particles can be temporarily hydrogenated by hydrogen evolved from $\mathrm{TiH}_{2}$ on heating. Absence of gaps around AP after dehydrogenation was completed (Fig. 4) gives an additional confirmation for that. It is important that for both compacts densification was noticeably better than that earlier observed for Ti-1023 alloy [2-3], in which visible gaps between AP and dehydrogenated titanium matrix formed on heating (See Fig. 2).

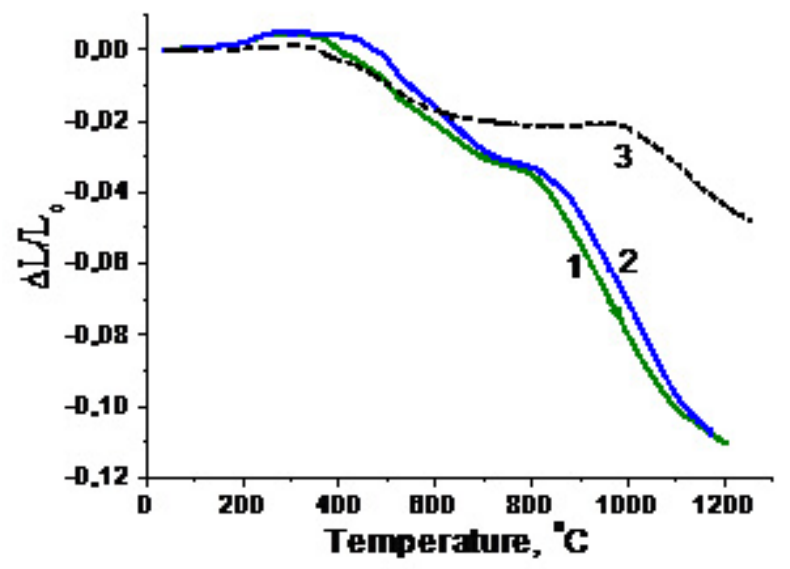

Fig. 3. Shrinkage curves for $\mathrm{TiH}_{2}$ based compacts, which overall composition correspond to Ti-185 alloy ( 1 and 2 represent compacts with hydrogenated and non hydrogenated AP powders respectively). For comparison, shrinkage curve of the Ti-1023 alloy is shown (3).

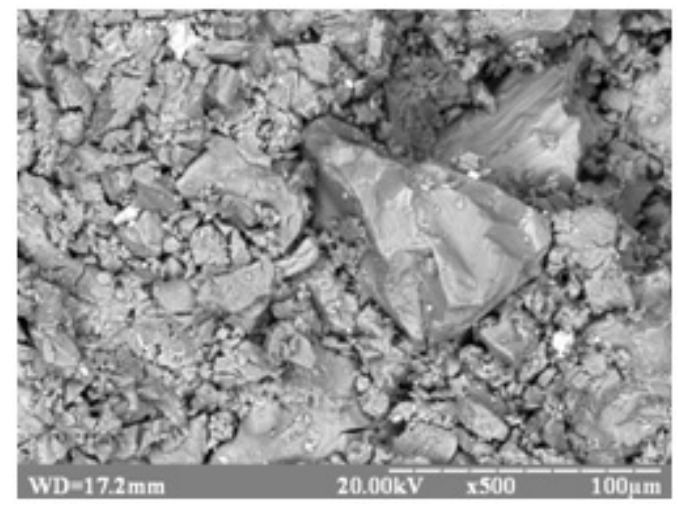


Fig. 4. Coarse AP surrounded by dehydrogenated Ti matrix with absence of gap formation around AP.

Although both above approaches have proved to be successful in $\mathrm{TiH}_{2}$ BEPM processing of the Ti-185 alloy with regard to its final density and chemical homogeneity, this was achieved at lower temperature and/or shorter time of sintering in the approach based on using preliminary hydrogenated AP, indicating on an important advantage of using the hydrogenated PAs. Therefore just this approach was used in $\mathrm{TiH}_{2}$ BEPM processing of low modulus titanium alloys.

\section{BEPM production of $\beta$ Ti-Zr-Nb and Ti-Zr-Nb-Ta alloys}

Conventional ingot/wrought processing of such alloys is hindered by high melting points of the components. Therefore their BEPM processing is of great interest. However, in turn, such processing is also challenging since mutual diffusivities of most their components are very low. These alloys are based on $\mathrm{Ti}$ - $\mathrm{Zr}$ system with addition of biocompatible $\beta$ stabilizers such as $\mathrm{Nb}$ and $\mathrm{Ta}$ [9]. As a first step, it was proposed to use $\mathrm{Zr}$ in the form of $\mathrm{ZrH}_{2}$ hydride. Advantage of $\mathrm{ZrH}_{2}$ over $\mathrm{Zr}$ powder in the sintering process [10] comes from its similarity with $\mathrm{TiH}_{2}$. Zirconium can be easily hydrogenated; brittle and low-strength $\mathrm{ZrH}_{2}$ phase is easily crushed to powder of desirable sizes; $\mathrm{ZrH}_{2}{ }^{\circledR} \mathrm{Zr}+2 \mathrm{H}$ phase transformation upon vacuum heating provides sintering activation. As a result, $\mathrm{TiH}_{2}+\mathrm{ZrH}_{2}$ compacts always are sintered to densities higher than $\mathrm{TiH}_{2}+\mathrm{Zr}$ compacts (Fig. 5). However, additions of $\mathrm{Nb}$ in accordance with $39 \mathrm{Ti}-35 \mathrm{Zr}-26 \mathrm{Nb}$ and $19 \mathrm{Ti}-59 \mathrm{Zr}-22 \mathrm{Nb}$ prescribed alloy compositions always lead to a significantly worse results. It was found that despite of low diffusion mobility of niobium, chemical homogeneity is possible to be achieved at high temperature sintering, but the final porosity remains high, typically in 6 to $9 \%$ range (Fig. 6). It is certainly a consequence of different behavior of the brittle hydride $\mathrm{TiH}_{2}+\mathrm{ZrH}_{2}$ part of the blend and ductile $\mathrm{Nb}$ particles. Hydrides are crushed on compaction and shrunk on heating leaving additional porosity around $\mathrm{Nb}$ particles. Combined with Kirkendall's type pores, the resulting porosity on the interfaces between $\mathrm{Nb}$ and $\mathrm{Ti}-\mathrm{Zr}$ matrix becomes high enough to be healed even at high temperatures. As it is seen from comparison of curves 1 and 3 (Fig. 7), addition of $\mathrm{Nb}$ particles to $\mathrm{TiH}_{2}+\mathrm{ZrH}_{2}$ blend results in a delayed shrinkage of powder compacts. 


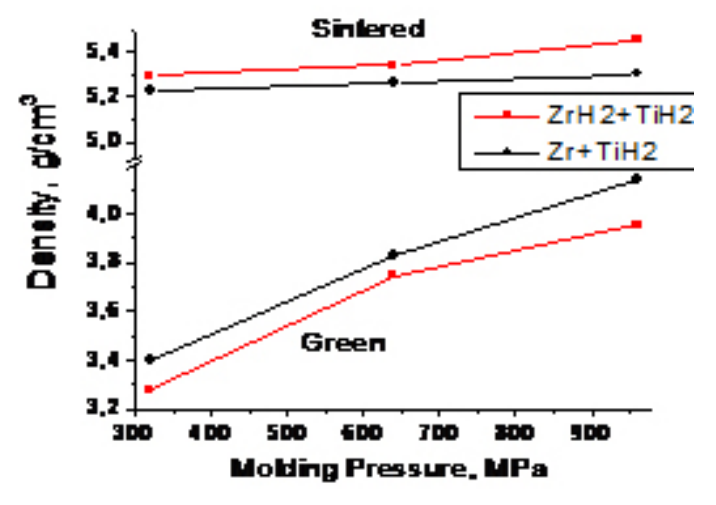

Fig. 5. Advantage of $\mathrm{ZrH}_{2}$ powder over $\mathrm{Zr}$ powder in achievement of higher sintered density of binary 50Ti-50Zr alloy.

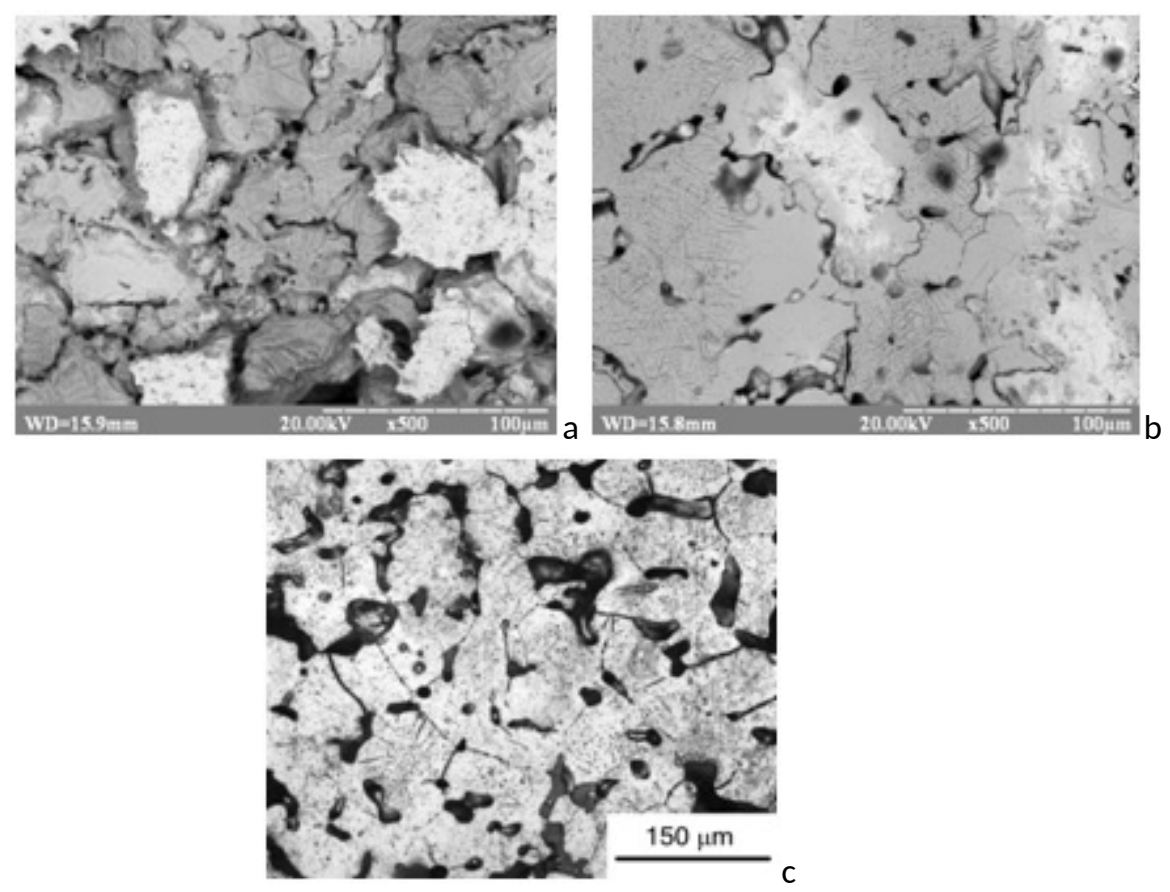

Fig. 6. Microstructure evolution of $39 \mathrm{Ti}-35 \mathrm{Zr}-26 \mathrm{Nb}$ alloy processed from $\mathrm{TiH}_{2}+\mathrm{ZrH}_{2}+\mathrm{Nb}$ powder compacts: (a) SEM, $1000^{\circ} \mathrm{C}$, (b) SEM, $1250^{\circ} \mathrm{C}$ and (c) $\mathrm{LM}, 1250^{\circ} \mathrm{C}, 4 \mathrm{~h}$. Bright areas in (a) and (b) are $\mathrm{Nb}$ particles or $\mathrm{Nb}$ rich diffusion zones. 


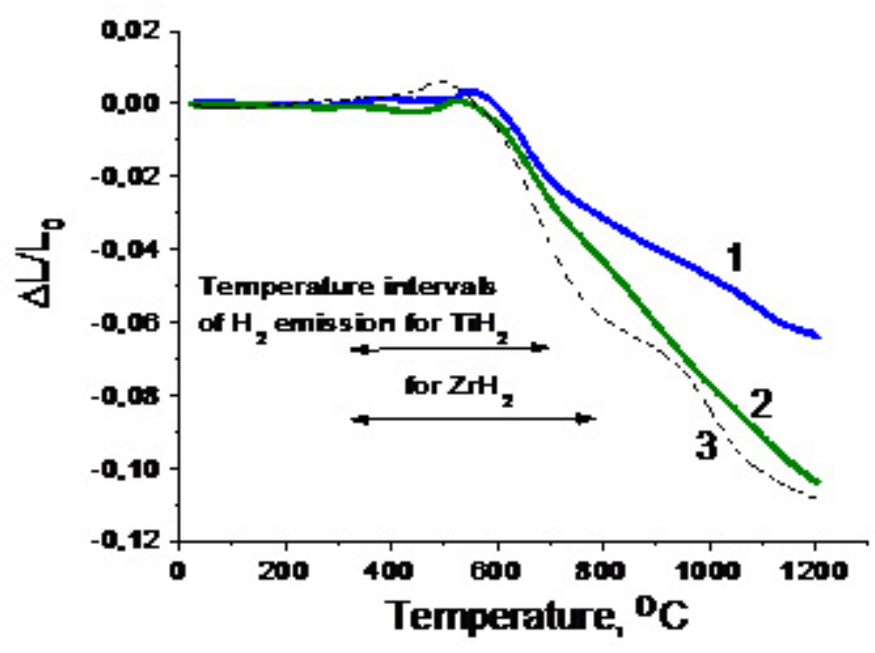

Fig. 7. Shrinkage curves for $\mathrm{TiH}_{2}+\mathrm{ZrH}_{2}$ based compacts of total 39Ti-35Zr-26Nb composition with: (1) $\mathrm{Nb}$ powder and (2) hydrogenated (Ti-Nb) $\mathrm{H}_{\mathrm{x}}$ AP. Curve for binary $\mathrm{TiH}_{2}+\mathrm{ZrH}_{2}$ compact is shown for comparison (3, dashed).

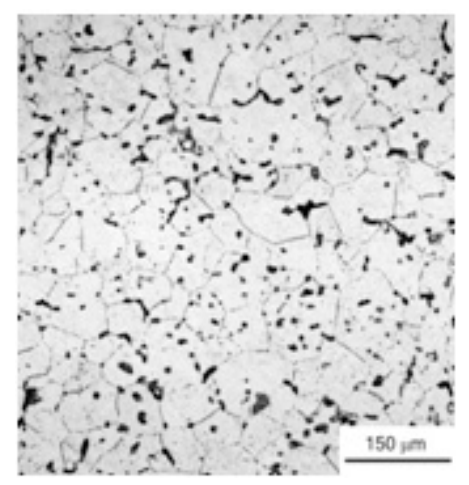

Fig. 8. Microstructure of 39Ti-35Zr-26Nb alloy BEPM processed using hydrogenated (Ti-Nb) $\mathrm{H}_{\mathrm{x}} \mathrm{AP}$ (compare with Fig. 6c).

Having in mind an aim to minimize the final porosity of $39 \mathrm{Ti}-35 \mathrm{Zr}-26 \mathrm{Nb}$ and $19 \mathrm{Ti}-59 \mathrm{Zr}-22 \mathrm{Nb}$ alloys, $\mathrm{Nb}$ powder was hydrogenated. However, that did not show any significant effect on the final 
result, since, as X-ray analysis showed, hydrogenated $\mathrm{Nb}$ had a two-phase $\mathrm{Nb}+\mathrm{NbH}$ structure, not brittle enough to be crushed upon compaction. Moreover, hydrogenated $\mathrm{Nb}$ was unstable in vacuum even at room temperature and therefore could not affect the microstructure evolution upon heating.

A noticeable decrease in the porosity down to $2 \%$ was achieved only when hydrogenated AP (Ti-Nb) $\mathrm{H}_{\mathrm{x}}$ was used (Fig. 8). The shrinkage of such compact (Fig. 7, curve 2) looks similar to that of the $\mathrm{TiH}_{2}+\mathrm{ZrH}_{2}$ without AP and much different from the shrinkage of the blend with Nb particles.

Following the above results, for synthesis of Ti-35Nb-7Zr-5Ta alloy all components were used in their hydrogenated form, including hydrogenated tantalum indentified as $\mathrm{TaH}$ phase. Its brittleness allowed its easy milling to powders of desirable sizes and compaction together with the $\mathrm{TiH}_{2}, \mathrm{ZrH}_{2}$ and $(\mathrm{Ti}-\mathrm{Nb}) \mathrm{H}_{\mathrm{X}}$. Hydrogen release from $\mathrm{TaH}$ started at about $300^{\circ} \mathrm{C}$. Sintering of such blended compacts resulted in a formation of low porous material. However, completed homogeneity was not achieved. Undissolved tantalum particles were observed in as-sintered material because of the extremely slow diffusion mobility of Ta $\left(5 \times 10^{-20} \mathrm{~m}^{2} / \mathrm{s}\right.$ at $1250^{\circ} \mathrm{C}$ [11], i.e. $7-8$ orders of magnitude lower than diffusivity of other elements at noted temperature).

To achieve a fully homogeneous alloy, two stage sintering process was developed. After intermediate sintering, as-sintered product was hydrogenated again and milled to produce prealloyed hydrogenated powder which was then compacted and sintered again at $1250^{\circ} \mathrm{C}, 4 \mathrm{~h}$. Such two stage sintering associated with double hydrogenation/dehydrogenation in order to activate diffusion resulted in a formation of completely uniform single-phase b-BCC microstructure with grain size of about $100 \mathrm{~mm}$ and not more than $2 \%$ porosity (Fig. 9).

Mechanical properties of the alloys manufactured with the modified $\mathrm{TiH}_{2} \mathrm{BEPM}$ approach are not analyzed in this paper. However, it is well known that three characteristics are important to achieve balanced properties of the PM processed titanium alloys. Those are high sintered density, not less than $98 \%$ of theoretical, admissible interstitial content according to alloy specifications, and uniform microstructure in which beta grain size is limited by $100-150 \mathrm{~mm}$. As it was shown above the modified $\mathrm{TiH}_{2}$ BEPM approach which main feature consists in using not only $\mathrm{TiH}_{2}$ but also all APs in their hydrogenated forms is capable to satisfy these requirements. As an example, low modulus Ti$35 \mathrm{Nb}-7 \mathrm{Zr}-5 \mathrm{Ta}$ alloy processed with the above approach exhibit excellent strength/ductility balance (Fig. 10). 


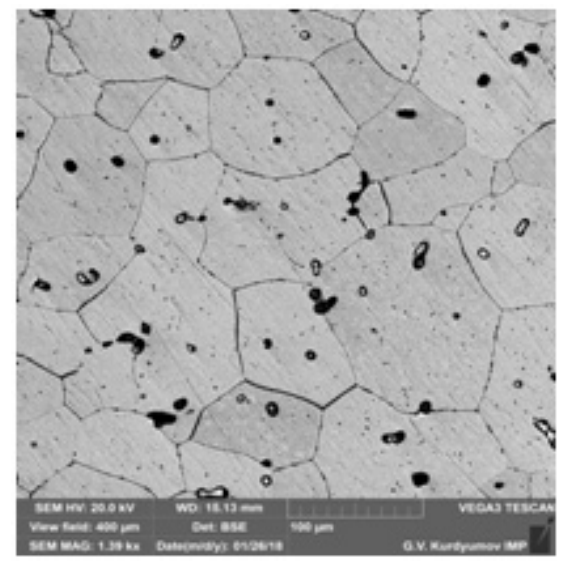

Fig. 9. Uniform Ti-35Nb-7Zr-5Ta alloy produced with sintering of hydrogenated prealloyed powder.

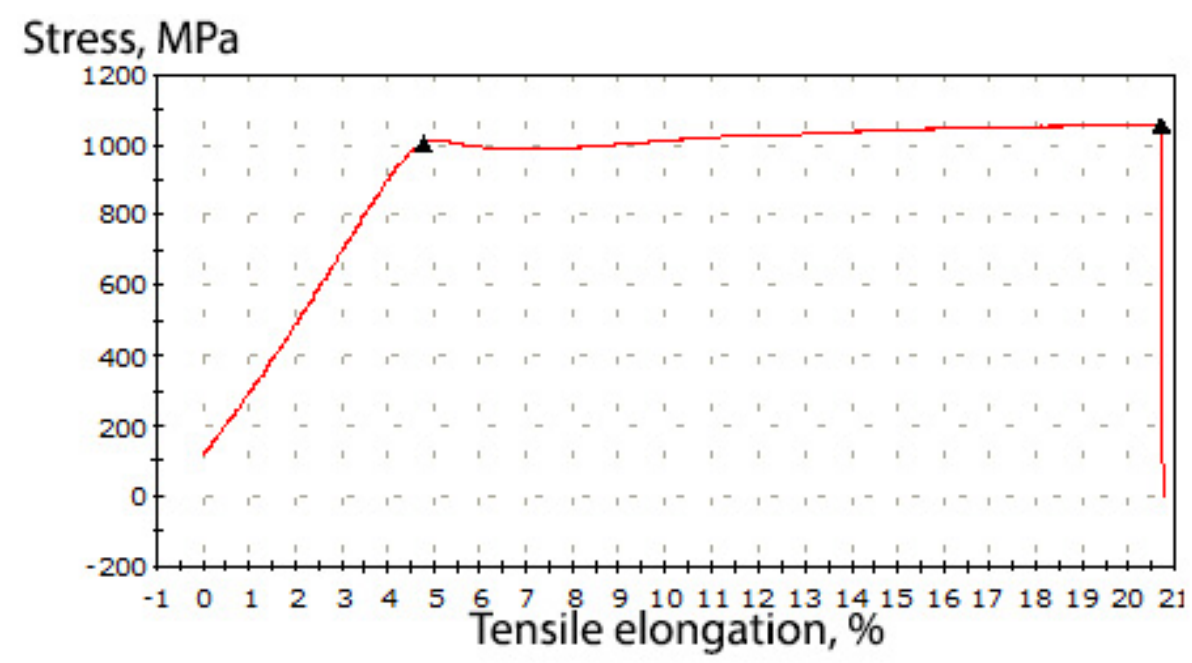

Fig. 10. Stress/strain tensile testing curve of as-sintered Ti-35Nb-7Zr-5Ta alloy.

\section{Conclusion}

The $\mathrm{TiH}_{2}$ BEPM of the heavily alloyed metastable $\beta$ alloys is complicated because of numerous interfaces between $\mathrm{TiH}_{2}$ and AP particles. A noticeable shrinkage of the $\mathrm{TiH}_{2}$ 
particles upon dehydrogenation provokes a volume mismatch between them and AP particles of different composition thus affecting integrity of compacted powder systems and resulting in an excess as-sintered porosity.

Use of hydrogenated alloying powders allows minimization of the above disadvantage of $\mathrm{TiH}_{2}$ BEPM. Low-porous, homogeneous $\beta$ alloys were processed with this approach, including alloys for medical application.

\section{$\underline{\text { References }}$}

[1] Titanium Powder Metallurgy: Science, Technology and Applications (Ma Qian, F.H.Froes, Eds.), Elsevier, 2015.

[2] O.M.Ivasishin, V.S.Moxson. Ibid, chapter 8, p.117-148.

[3] O.M.Ivasishin, D.G.Savvakin. Key Engineering Materials, v. 436 (2010) p.113-121.

[4] O.M.Ivasishin, D.G.Savvakin, M.M.Gumenyak, A.B.Bondarchuk. Key Engineering Materials, v.520, 2012, p.121-132.

[5] F.H.Froes, D.Eylon, Inter. Mater. Rev.-1990. -v.35, No. 3. - p.162-182.

[6] S.M.El-Soudani, K.-O. Yu, E.M.Crist et al. Metallurgical and Materials Transactions A, v. 44A, 2013, p. 899-910.

[7] Joshi, V.V.; Lavender, C.; Moxson, V.S. at al, Journal of Materials and Engineering Performance, 2013, 22, 995-1003.

[8] O.M.Ivasishin, D.G.Savvakin et al. Materials Science, 53, 2, 2018, p.121-127.

[9] M.Niinomi, M.Nakai, J.Hieda. Acta Biomaterialia, 8, 2012, 3888-3903.

[10] O.M.Ivasishin, D.G.Savvakin. Materials Science, 51, 4, 2016.

[11] K.Wang, R.Reeber, High Temperature and Materials Science, v.36, 1996, p.185-193. 